\title{
Heterotopic acinic cell carcinoma and its clinical implications
}

\author{
Ivo Starek ${ }^{\mathrm{a}}$, Richard Salzman ${ }^{\mathrm{a}}$, Alena Skalova ${ }^{\mathrm{b}}$
}

This is a review of the clinical and histopathological published data on very rare heterotopic acinic cell carcinomas (AcCCs) with suggested optimal management. Extrasalivary AcCCs originate primarily in parotid lymph nodes. They present at low clinical stage, show mostly low-grade histopathology and are circumscribed with a complete nodal capsule. Extracapsular dissection was advocated as adequate therapy. In rare cases with positive surgical margins, a completion parotidectomy or adjuvant radiotherapy should follow. Heterotopic high-grade AcCCs are rare, necessitating radical surgery including neck dissection and adjuvant radiotherapy. The short term prognosis is excellent, long term outcomes are not known. Longer term follow-up is essential.

Key words: acinic cell carcinoma, heterotopia, lymph node, salivary gland

Received: August 15, 2020; Revised: September 23, 2020; Accepted: October 5, 2020; Available online: November 10, 2020 https://doi.org/10.5507/bp.2020.047

(c) 2021 The Authors; https://creativecommons.org/licenses/by/4.0/

${ }^{a}$ Department of Otorhinolaryngology and Head and Neck Surgery, University Hospital Olomouc and Faculty of Medicine and Dentistry, Palacky University Olomouc, Czech Republic

${ }^{b}$ Department of Pathology, Faculty of Medicine in Plzen, Charles University Prague, Czech Republic

Corresponding author: Richard Salzman, e-mail: richard.salzman@fnol.cz

\section{INTRODUCTION}

Heterotopic (ectopic) salivary tumours arise from neoplastic transformation of aberrant salivary tissue present outside the "orthotopic" major, minor and accessory salivary glands. Salivary heterotopias occur rarely in lymph nodes and extremely sporadically in various extranodal head and neck locations where they clinically appear as soft tissue masses. In cephalic positions, they are believed to be portions of salivary gland rudiments dislocated during embryonic development. Moreover, they can be found in anterior ${ }^{1}$ and exceptionally also in the posterior neck ${ }^{2}$, here presenting as a nontender swelling and/or scantily draining sinus. Cervical salivary heterotopias occurring near the sternoclavicular joint or those associated with branchiogenic and thyreoglossal malformations are postulated to be heteroplasias of ectodermal remnants of the precervical sinus of His or thyreoglossal duct. A similar mechanism seems to be involved in the development of heterotopic salivary tissue in the breast ${ }^{3}$, gastrointestinal ${ }^{4}$ and urogenital tract ${ }^{5}$.

The majority of salivary heterotopias occur in the parotid and suprahyoid lymph nodes. They are composed of intercalated, striated or intralobular ducts, serous acini may be present occasionally ${ }^{6}$. Intranodal location of salivary tissue, as well as the presence of lymph nodes in the parotid, can be explained by the intermingling of salivary primordia and condensating mesenchyma of the second branchial arch occurring in the 7th embryonal week. Brown ${ }^{7}$ found salivary tissue in intraparotid lymph nodes in all of 19 autopsied newborns. In some adults, the heterotopic intranodal salivary tissue persists and may clinically mimic a tumour due to various histological changes of the epithelium ${ }^{8}$.
Generally, except for Warthin tumour, extrasalivary sialomas are extremely rare lesions. Seifert ${ }^{9}$ in a series comprising 6686 salivary gland tumours, found only three cases arising in intraparotid lymph nodes. Similarly, Warnock ${ }^{10}$ and Daniel ${ }^{11}$ reported solely 8 and 7 analogic cases, respectively, during a 25 -year period.

In the histopathologic spectrum of heterotopic intranodal sialomas benign lesions prevail. Among them, Warthin's tumour is the predominant entity, followed by much less frequent pleomorphic adenoma ${ }^{11-13}$. In the malignant group, the commonest tumours are high- and low-risk mucoepidermoid carcinomas and acinic cell carcinomas (AcCCs), other entities (such as oncocytic carcinoma, sialoblastoma, salivary duct carcinoma, adenoid cystic carcinoma, myoepithelial carcinoma) occur sporadically $y^{9,11,13-20 .}$

Intranodal occurence of a salivary carcinoma which is not associated with a tumour arising from an "orthotopic" salivary gland raises a question whether it represents a heterotopic or metastatic lesion from an unknown primary. An inappropriate decision jeopardizes the patient with treatment failure of the primary neoplasm or unnecessary surgery of an adjacent tumour free salivary gland with its associated morbidity. The solution to that dilemma is based on the three following criteria ${ }^{16,21}: 1$. no primary "orthotopic" carcinoma detected clinically or using relevant imaging methods. 2. microscopic evidence of glandular ductal and/or acinar inclusions in the affected lymph node. However, the absence of these structures does not exclude the diagnosis of an ectopic tumour, since they may be replaced by carcinoma cells. Besides, one must keep in mind that both events might at least theoretically, coincide. 3 . the tumour must be completely embedded within nodal tissue which is sharply demarcated from 
the parenchyma of the "orthotopic" salivary gland. The primary intranodal origin of a salivary carcinoma is further supported by its predominant central growth which corresponds with occurence of salivary inclusions in this location. In equivocal cases, a definite conclusion can be achieved solely by a long-term follow-up.

Intranodal origin of $\mathrm{AcCC}$, both primary or metastatic, may be challenging in cases endowed with lymphoid stroma $^{22}$ which is easily mistakable for a lymph node ${ }^{23}$. In these cases, evidence of residual anatomical structures of the latter (i.e. medular or subcapsular sinuses or a hilum) is usually critical.

Management of the "orthotopic" salivary carcinomas is specified in generally accepted guidelines NCCN $\left(\right.$ ref. $\left.{ }^{24}\right)$. However, the extreme rarity of heterotopic salivary carcinomas and the consequent absence of relevant data with resulting uncertainty in their biological character precludes implementation of therapeutic standards. Surgical procedures in heterotopic AcCCs which are being typically diagnosed postoperatively may vary from extensive to limited. The latter is occasionally followed by completing surgery and adjuvant radiotherapy.

In the current WHO classification, AcCC is categorized as a low-risk lesion Simpson ${ }^{25}$. However, individual cases may demonstrate a protracted, unpredictable and potentially fatal clinical course. Therefore, clinicopathologic features, therapeutic strategies and prognosis of major and minor salivary gland AcCCs were quite recently reviewed in a comprehensive analysis consisting of 156 reference ${ }^{26}$. We believe that the results should be adopted for the heterotopic variant of this carcinoma, enabling thus optimal individual treatment.

\section{RESULTS}

Our literature research identified only 18 cases of heterotopic AcCCs. Four of them, reported by Abrams ${ }^{27}$ and
Evans ${ }^{28}$ were not properly described. Sufficient data were available in other 14 patients (including our one) presented by 10 independent authors ${ }^{9,11,16,21,29-34}$ (see Table 1).

Except for a carcinomas originating presumably from aberrant extranodal salivary tissue of the upper neck (pt. 12), all other 13 tumours arose from low- or mid-cervical (pts. 1, 4 and 6), intra- (pts. 2, 8, 9,10, 11, 13 and 14) and paraparotid intranodal (pts. 3, 5 and 7) salivary heterotopias. In 12 patients in whom gender was known, a considerable (10 to 2 ) female preponderance was noticed. The age varied from 7 to 62 (mean 36.9) years. The size of particular tumours that was available in 9 cases did not exceed $3.5 \mathrm{~cm}$, seven of which were less than $3 \mathrm{~cm}$. Six of seven carcinomas were mobile, in the other seven cases, no relevant information was provided. In pt. 4 local findings was suspicious of malignancy.

Except for a carcinoma originating presumably from aberrant extranodal salivary tissue of the upper neck (pt. 12), all other 13 tumours arose from low- or mid-cervical (pts. 1, 4 and 6), intra- (pts. 2, 8, 9, 10, 11, 13 and 14) and paraparotid intranodal (pts. 3, 5, 7) salivary heterotopias.

Relevant treatment data were available in all but one (pt. 9) patient. Nine intra/paraparotid intranodal tumours were treated using a simple excision alone (pts. 1, 12 and 14) or in combination with adjuvant radiotherapy (pt. 2, 7) or a superficial/partial parotidectomy without (pts. 3, 5,8 , and 13) or with neck dissection (pts. 10, 11). The latter procedure was subsequently followed by a completion parotidectomy (pt. 13). In three of four patients with carcinomas located in the upper or lower neck, simple resection alone (pts. 1 and 12) or completed with superficial parotidectomy (pt. 6) was performed. In the pt. 4 , the treatment consisted of comprehensive neck dissection, superficial parotidectomy and resection of the submandibular gland. All patients presented as cN0. The histopathologic nodal status could be evaluated only in 5 patients after a neck dissection (pts. 4, 10 and 11) or nodal excision (pt. 3 and 8). A metastasis was demonstrated

Table 1. Previously reported cases of heterotopic acinic cell carcinoma.

\begin{tabular}{|c|c|c|c|c|c|c|c|}
\hline No, author & Sex, age (y) & Loc. & Size $(\mathrm{cm})$ & Mobility & Therapy & f-up (mo) & Ref. \\
\hline 1. Bhaskar & M, 17 & IN, LN & NA & NA & $\mathrm{E}$ & NA & 29 \\
\hline 2. Kleinsasser & $\mathrm{F}, 47$ & IN, IP & chestnut & semifixed & $\mathrm{E}+\mathrm{RT}$ & NA & 30 \\
\hline 3. Perzin & $\mathrm{F}, 18$ & IN, PP & $3.5 \mathrm{~cm}$ & mobile & ParP & 12, NED & 21 \\
\hline 4. Perzin & F, 66 & IN, MN & $2.5 \mathrm{~cm}$ & NA & $\mathrm{SP}+\mathrm{ND}+\mathrm{SGE}$ & 12 , fem. meta & 49 \\
\hline 5. Yacoub & $\mathrm{F}, 7$ & IN, PP & $2 \mathrm{~cm}$ & mobile & SP & 12, NED & 31 \\
\hline 6. Zajtchuk & M, 10 & IN, LN & NA & NA & $\mathrm{E}+\mathrm{SPE}$ & 45, NED & 16 \\
\hline 7. Zajtchuk & $\mathrm{F}, 47$ & IN, PP & NA & NA & $\mathrm{E}+\mathrm{RT}$ & 10, NED & 16 \\
\hline 8. Minic & $\mathrm{F}, 37$ & IN, IP & $2.5 \mathrm{~cm}$ & mobile & SP & 20, NED & 32 \\
\hline 9. Seifert & $F, 62$ & IN, IP & $1.6 \mathrm{~cm}$ & NA & NA & NA & 9 \\
\hline 10. Daniel & NA & IN, IP & NA & NA & $\mathrm{SP}+\mathrm{ND}(\mathrm{N} 0)$ & NA & 11 \\
\hline 11. Daniel & NA & IN, IP & NA & NA & $\mathrm{SP}+\mathrm{ND}(\mathrm{N} 0)$ & 24, NED & 11 \\
\hline 12. Das & $\mathrm{F}, 32$ & ExN, UN & $1.5 \mathrm{~cm}$ & mobile & $\mathrm{E}$ & NA & 33 \\
\hline 13. Alsayegh & F, 38 & IN, IP & $2 \mathrm{~cm}$ & mobile & $\mathrm{SP}+\mathrm{TP}$ & NA & 34 \\
\hline 14. our patient & $F, 62$ & IN, PP & $1.3 \mathrm{~cm}$ & mobile & $\mathrm{E}$ & 24, NED & \\
\hline
\end{tabular}

PP paraparotid, IP intraparotid, IN intranodal, ExN extranodal, LN lower neck, UN upper neck, MN middle neck, EN encapsulated, SM surgical margins, E excision, SP superficial parotidectomy, TP total parotidectomy, ND neck dissection, SGE submandibular gland excision, ParP partial parotidectomy, NA not available 


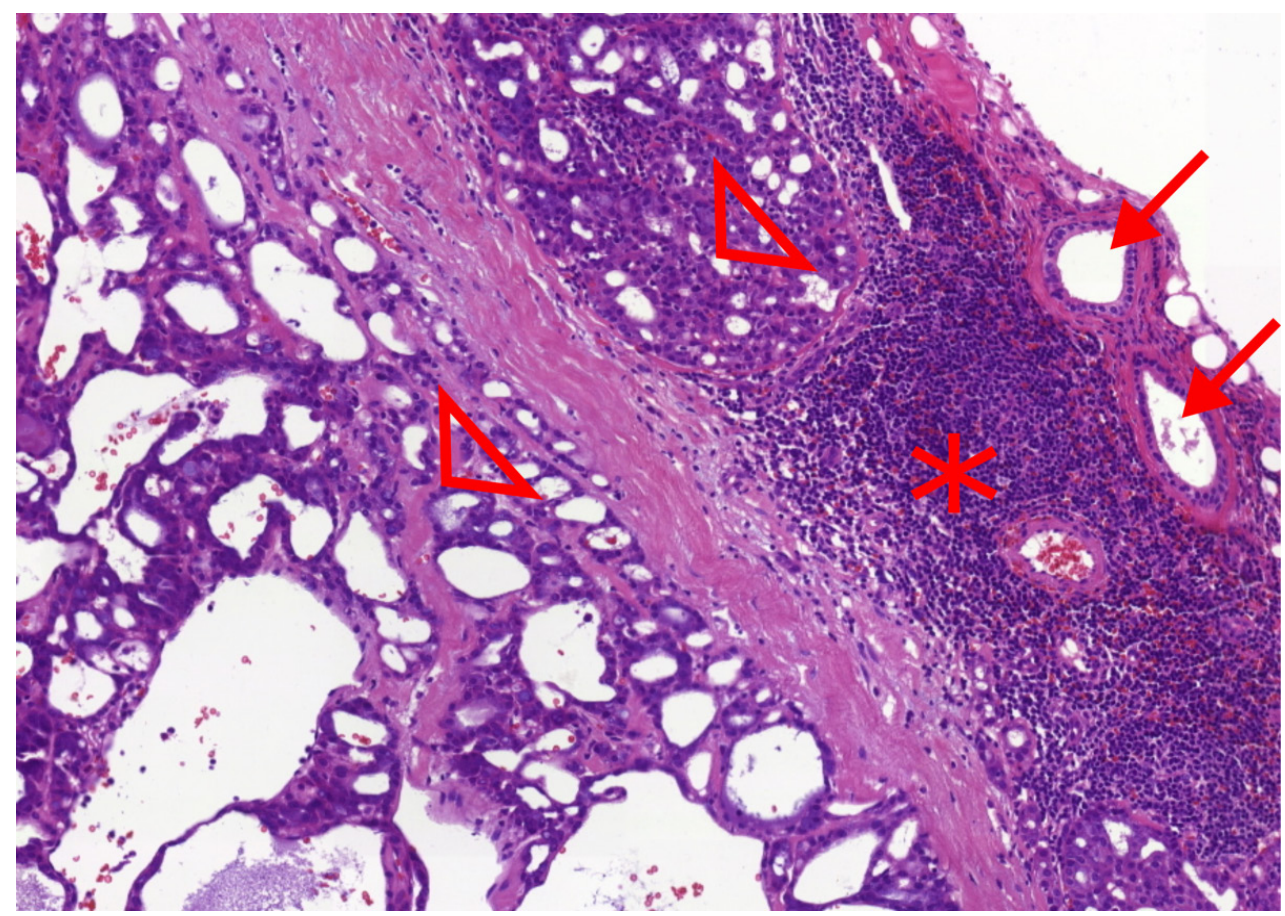

Fig. 1. Heterotopic intranodal AcCC showing a solid-microcystic pattern (triangles) in patient 14. The nodal lymphoid tissue (asterisk) is pushed to the tumour periphery covered with a thin rim of fibrous tissue with two intranodal salivary inclusions represented by dilated duct (arrows). (H.E.)

only in the patient No. 4, in whom the tumour showed foci of dedifferentiation. Information on the quality of the nodal capsule was available in 6 patients. In four of them (pts. 2, 5, 8, 9), the capsules were tumour-free. A slight capsular invasion was present only in the pt. 13 and in the pt. 14, the capsule was focally absent (Fig. 1). In all cases, in which parotidectomy specimens were obtained, the overlying parotid tissue was free of carcinoma (pts. 3, $8,5,9,13)$. Aberrant intranodal salivary inclusions were seen only in pts. 8, 13 and 14 (Fig. 1).

Follow-up ranging from one 10 to 45 (mean 19,9) months was obtained in eight atients. All were alive and excluding the patient 4 , with no evidence of disease.

As far as it can be assessed from histopathologic descriptions of particular cases, the majority of them showed a histopathologic pattern of a conventional lowgrade $\mathrm{AcCC}$, areas of dedifferentiation were present solely in the patient pt. 4 .

\section{DISCUSSION}

AcCC accounts for about $11 \%$ of all salivary malignancies. About $90 \%$ of cases originate from the parotid and the remaining from other major and minor, primarily buccal and upper lip glands Biron ${ }^{35}$. With a slight female prevalence, the AcCCs are evenly distributed throughout all decades with the proclivity to occur at a younger age than other salivary gland carcinomas. Children are affected very rarely ${ }^{26,36-39}$. AcCCs are diagnosed mostly at initial clinical stages ${ }^{39}$. The presented review demonstrates that the sex and age distributions of heterotopic AcCCs meet those arising in the parotid. Moreover, like the majority of "orthotopic" AcCCs, they are asymptomatic, freely mobile, not sizable, and slowly progressing lesions.

Although considered to be the most favourable among all salivary gland carcinomas, AcCC must not be labelled innocent. Prior institutional studies mentioned the 5, 10 and 15 -year survival rates to reach about $83 \%, 76 \%$ and $65 \%$, respectively Spiro ${ }^{40}$. However, the results might have been distorted by referral/selection bias. A recent population-based study is more optimistic, indicating 97\%, 94\% and $90 \%$ overall surival at 5, 15 and 20 years, respectively Patel $^{37}$.

Vagarity in the clinical course of AcCCs had initiated attempts at identification of prognostic factors, applicable in its management. A large multivariate analysis was performed elaborating data of a total of 3345 AcCC patients collected by three independent institutions. In this analysis, increasing age, male gender, non-caucasian race, minor salivary gland origin, positive resection margins, inadequate previous treatment, irradical resection, TNM parameters, proliferative activity, and tumour grade proved to be adverse factors ${ }^{26}$.

Histopathological grading of $\mathrm{AcCC}$ has not been suggested in the current WHO classification of salivary gland tumours ${ }^{25}$. Nontheless, its prognostic relevance was recently confirmed by Gomez ${ }^{41}$ demonstrating the 5-year disease-free/overall survival rates to be $94 / 100 \%$ and $54 / 69 \%$ for low- and high-grade tumours, respectively. Prognosis in patients diagnosed with AcCCs largely deteriorates with the occurence of high-grade transformation. 
These cases are significantly associated with lymph node and distant metastasis with about two-thirds of them dying from the disease after a median of 4.3 years Skálová ${ }^{42}$.

All but one analyzed patients were alive and diseasefree. The only exception was the patient with dedifferentiated $\mathrm{AcCC}$ who had developed a femoral metastasis and may have died of the tumour. However, the follow-up of particular cases was too short, not covering the potentially very prolonged and fatal course, known in the parotid AcCCs. The time patients with these neoplasms should be followed-up, necessitates at least ten years ${ }^{43}$. The longterm prognosis of ectopic AcCCs thus remains unclear. It is not clear whether it equals that of the parotid or minor salivary gland AcCCs. The prognosis of the latter group was reported to be less favourable, i.e. 25-year survival rate and incidence of metastasis making 50 and $20 \%$, respectively ${ }^{44}$. The worse outcome is related to the preponderance of high grade pathology ${ }^{35}$ and common infiltrative growth ${ }^{27}$. Moreover, some adverse anatomic locations and invariably lacking capsule increase the risk of incomplete resection of minor salivary AcCCs.

Rational treatment of salivary carcinomas is a complete resection aiming at achieving tumour-free margins. On account of inconsistent encapsulation and occasional extracapsular extensions, the AcCCs must be removed (as well as all other low-risk salivary carcinomas) along with a rim of a tumour-free surrounding tissue. For those originating from the parotid, superficial or total parotidectomy dependently from the stage and tumour location ( $\mathrm{su}-$ perficial vs. deep parotid lobe), are usually preferred ${ }^{40,41}$. However, in benign looking low-stage/low-grade salivary carcinomas, some authors perform extracapsular dissection to reduce postoperative morbitidy. $\mathrm{McGurk}^{45} \mathrm{com}-$ pared results in 12 patients treated with that method vs. 20 others who had undergone a superficial parotidectomy. Positive or close resection margins were present in $41 \%$ and $35 \%$ of them, respectively, with this difference being insignificant. Mantsopoulos ${ }^{46}$ performed completion parotidectomy in 25 carcinomas, 22 of which were categorized as low-grade. Residual neoplastic cells were found only in $3(12 \%)$ of them. In his previous study, the author ${ }^{47}$ reported no evidence of disease in patients with low-grade salivary carcinomas treated exclusively with extracapsular dissection. Unfortunately, the total of AcCC cases enrolled in these three series was minimal.

Extracapsular dissection eliminates potential microscopic foci of neoplastic cells extending into the closely overlying tissues. Unlike mostly unencapsulated "orthotopic" AcCCs, the intranodal heterotopic ones are fenced with a nodal capsule acting as a potentional barrier against the spread of neoplastic cells into adjacent tissues. In our review, the majority of carcinomas revealed a complete and tumour free nodal capsule. Capsular break associated with a minimal tumour extension beyond the relevant lymh node was found solely in one case. Bernier ${ }^{48} \mathrm{dem}$ onstrated that the capsule of parotid lymph nodes may be focally incomplete. That phenomenon was present in our patient 14. In this case, instead of the lacking part of the capsule, the tumour was covered by a thin rim of fibrous tissue. We, therefore, believe that extracapsular dissec- tion is sufficient for intranodal heterotopic AcCCs. Our opinion is supported by Perzin ${ }^{49}$ reporting no recurrences of apparently well-circumscribed orthotopic" AcCCs. Moreover, the prognosis of the latter tumours was proved to be unrelated to the extent of resection ${ }^{38}$. Respecting these findings, we assume that patients with low-grade heterotopic AcCCs surrounded by an intact nodal capsule should be spared a completion parotidectomy.

We could find only a single case of extranodal heterotopic AcCC with unavailable information on the capsule quality. We can but speculate that this would be analogous to that in the major or small salivary gland AcCCs, i. e. incomplete or even absent, necessitating thus resection with a generous rim of adjacent tissue. Because of extreme scarcity, the extranodal heterotopic AcCCs are usually not taken into differential diagnostic considerations of neck masses. Consequently, the surgery would most probably have explorative character, hardly reaching negative resection margins. However, cervical location of extranodal heterotopic AcCCs makes a revision surgery easy, not associated with significant postoperative morbidity.

In the current analysis, only the patient with dedifferentiated AcCC showed multiple nodal metastasis, all others were staged as N0. The low lymphangiogenous spread accords well with the reported merely $10 \%$ incidence of nodal involvement in "orthotopic" AcCCs which is usually associated with high-grade features and/or advanced T stage ${ }^{38}$. An elective neck dissection is, thus, not recommended in the extrasalivary AcCCs, unless they show the latter two characteristics.

In our review, two patients ( 2 and 7 ) received adjuvant radiotherapy after a simple resection of benign-looking intranodal heterotopic AcCC. Indications for the RT were not stated explicitly by the referring authors. On the other side, the patient (No. 4) with a dedifferentiated carcinoma revealing nodal metastases, received extensive surgery only and developed a femoral metastasis one year later. These cases illustrate ambiguity in the view on adjunctive radiotherapy in heterotopic AcCCs. That issue in "orthotopic" AcCCs was addressed largely by Vander Poorten et al. ${ }^{26}$. After a thorough and critical literature review, the author summarized that in analogy with other salivary gland carcinomas, additional radiotherapy should be given in cases with T3/T4 stages, high-grade histopathology, high proliferative index, regional lymphatic metastasis, positive surgical margins, perineural invasion and salvage surgery for tumour recurrence. The limited number of published heterotopic AcCCs and inadequate follow-ups preclude any solid guidelines regarding criteria for radiotherapy of these lesions. However, in our opinion, they should be analogous with those applied for the common AcCCs.

\section{CONCLUSION}

Extrasalivary AcCCs are very rare lesions. They originate mostly from intra- or paraparotid intranodal salivary heterotopias. Presenting as clinically benign lesions, they are diagnosed typically at low-clinical stage. Because of 
prevalence of low-grade histopathology and node capsule at the periphery of intranodal AcCCs, the authors advocate extracapsular dissection as adequate therapy. In cases with positive surgical margins, a completion parotidectomy or adjuvant radiotherapy should follow. Heterotopic high-grade AcCCs are rare, necessitating radical surgery including neck dissection and adjuvant radiotherapy. Short term prognosis of heterotopic intranodal AcCCs is generally excellent, long term outcomes are not known. Consequently, an adequate follow-up is essential.

\section{Search strategy and selection criteria}

The PubMed and Embase databases were searched with the Medical Subject Headings (key-words: acinic cell carcinoma, lymph node, salivary gland, heterotopia). A manual search of the bibliografy of relevant studies was also performed to identify additional papers. The date of publication and language were not restricting selection criteria.

Only cases of AcCCs declared by particular authors to meet the above-mentioned criteria for heterotopic origin were included. Controversial may be considered one of the two patients reported by Perzin et al. ${ }^{21}$. In this case, an intranodal AcCC was found in the middle neck and metastatic cells were detected also in many adjacent lymph nodes. The resected ipsilateral submandibular gland and superficial parotid lobe were free of carcinoma. The authors speculated that a microscopic primary might have gone undetected in the deep parotid but stated that he was not aware of any occult AcCC to develop metastases. In another patient ${ }^{50}$, a dedifferentiated AcCC was completely embedded in an intraparotid lymph node. However, a microscopic, supposedly primary carcinoma was found in the resected superficial parotid lobe. Ectopic origin of that tumour is, therefore, debatable and the case could not be accepted.

Acknowledgement: The study was supported by Ministry of Health of the Czech Republic - DRO (FNO1, 00098892) and the Internal Grant of Palacký University IGA LF 2020-27.

Author contributions: All authors contributed to the study conception and design. IS: came with the idea, designed the review, performed literature search, data analysis, and wrote the manuscript; RS: performed data analysis, reviewed manuscript, and prepared submission; AS: reviewed the manuscript. All authors read and approved the final manuscript.

Conflicts of interest statement: None declared.

\section{REFERENCES}

1. Haemel A, Gnepp DR, Carlsten J, Robinson-Bostom L. Heterotopic salivary gland tissue in the neck. J Am Acad Dermatol 2008;58:25156.

2. Marshall JN, Soo G, Coakley FV Ectopic salivary gland in the posterior triangle of the neck. J Laryngol Otol 1995;109:669-70.

3. Maffini F, Pisa E, Possanzini P, Viale G Salivary gland choristoma of breast. Breast J 2012;18:181.

4. Offner FA, Langner C. Heterotopic tissue in the gastrointestinal tract. Pathologe 2018;39:402-408.
5. Marwah S, Berman ML. Ectopic salivary gland in the vulva (Choristoma): Report of a case and review of the literature. Obstet Gynecol 1980;56:389-91.

6. McHugh JB. Major and minor salivary glands. In: Goldblum JR, Lamps LW, McKenny JK. Myers JL (eds) Rosai and Ackerman's Surgical Pathology, 11th edn. Elsevier, Philadelphia, 2018, pp 38-45.

7. Brown RB, Captain MC, Gaillard RA, Turner JA. The significance of aberrant or heterotopic parotid gland tissue in lymph nodes. Ann Surg 1953;138:850-56.

8. Shinohara M, Harada T, Nakamura S, Oka M, Tashiro H. Heterotopic salivary gland tissue in lymph nodes of the cervical region. Int J Oral Maxillofac Surg 1992;21:166-71.

9. Seifert G. Primäre Speicheldrüsentumoren in Lymphknoten der Parotis. Pathologe 1997;18:141-46.

10. Warnock GR, Jensen JL, Kratochvil FJ. Developmental diseases. In. Ellis GL, Auclair PL, Gnepp DR (eds) Surgical pathology of the salivary glands. Saunders, Philadelphia, 1991.

11. Daniel, E, McGuirt WF. Neck massess secondary to heterotopic salivary gland tissue: a 25-year experience. Am J Otolaryngol 2005;26:96-100.

12, Gudbrandsson FK, Liston SL, Maisel RA. Heterotopic salivary tissue in the neck. Otolaryngol Head Neck Surg 1982;90:279-82.

13. Ferlito A., Bertino G., Rinaldo A., Mannara GM, Devaney KO. A review of heterotopia and associated salivary gland neoplasms of the head and neck. J Laryngol Otol 1990;113:299-303.

14. Singer MI, Applebaum EL, Loy KD. Heterotopic salivary tissue in the neck. Laryngoscope 1979;89:1772-78.

15. Teymoortash A, Ramaswamy A, Werner JA. Adenoidzystisches Karzinom im heterotopen Speicheldrüsengewebe der zervikalen Lymphknoten. Laryngo-Rhino-Otologie 2007;86:44-47.

16. Zajtchuk CJ, Patow CA, Hyams VJ. Cervical heterotopic salivary gland neoplasms: a diagnostic dilemma. Otolaryngol Head Neck Surg 1982;90:178-81.

17. Marucci DD, Lawson K, Harper J, Sebire NJ, Dunaway DJ. Sialoblastoma Arising in Ectopic Salivary Gland Tissue. J Plast Reconstr Aesthet Surg 2009;62:241-46.

18. Suzuki H, Hashimoto K. Salivary duct carcinoma in the mandible: Report of a case with immunohistochemical studies J Oral Maxillofac Surg 1999;37:67-69.

19. Brookstone BS, Huvos AG, Spiro RH. Central Adenoid Cystic Carcinoma of the Mandible. Oral Maxillofac Surg 1990;48:1329-33.

20. Martinoli C, Cittadini G, Derchi LE, Rollandi GA, Chiaramondia M. Malignant Myoepithelioma Arising in Salivary Tissue on the Masseter Muscle: US, CT, and MR Findings. J Comput Assist Tomogr 1996;20:119-21.

21. Perzin, KJ, Livolsi VA. Acinic cell carcinoma arising in ectopic salivary gland tissue. Cancer 1980;45:967-72.

22. Michal M, Skálová A., Simpson RHW, Ryška A, Stárek I. Well differentiated acinic cell carcinoma of salivary glands associated with lymphoid rich stroma. Hum Pathol 1997;28:595-600.

23. Abdelkrim SB, Kermani W, Beizig N, Ziadi S, Belkadhi M, Sriha B, Mokni M. Acinic cell carcinoma with lymphoid stroma mistaken for a metastatic intraparotid lymph node at frozen section analysis. J Case Reports in Practice (JCRP) 2013;2:41-44.

24. NCCN Guidlines Version 1.2015. Salivary gland tumors.

25. Simpson RHW, Chiosea S, Katabi N. Acinic cell carcinoma. In: ElNaggar AK, Chan JKC, Grandis JR, Slootweg PJ, eds. World Health Organization (WHO) Classification of Head and Neck Tumours, 4th edition. IARC Press, Lyon, France 2017. pp 166-167.

26. Vander Poorten V, Triantafyllou A, Thompson LDR, Bishop J, Hauben E, Hunt J, Skalova A, Stenman G, Takes RP et al. Salivary acinic cell carcinoma: reappraisal and update. Eur Arch Otorhinolaryngol 2016;273:3511-31. doi: 10.1007/s00405-015-3855-7

27. Abrams AM, Cornyn J, Scoffield HH, Hansen LS. Acinic cell adenocarcinoma of the major salivary glands. A clinicopathologic study of 77 cases. Cancer 1965;18:1145-62.

28. Evans RW, Cruickshank AH. Epithelial tumours of the salivary glands. Major Probl Pathol 1970;1:1-299.

29. Bhaskar SN. Acinic cell carcinoma of salivary glands. Report of twenty-one cases. Oral Surg Oral Med Oral Pathol 1964;17:62-74.

30. Kleinsasser O, Hubner G, Klein HJ. Acinuszelltumoren der Glandula parotis. Arch Klin Exper Ohren, Nasen und Kehlkopfheilk. 1967;33-50.

31. Yacoub U, Carstens PH, Biscopink RJ, McMurry GT. Acinic-cell tumor in ectopic salivary-gland tissue. Arch Pathol Lab Med 1981;105(9):500-501 
32. Minic AJ. Acinic cell carcinoma arising in a parotid lymph node. Int J Oral Maxillofac Surg 1993; 22:289-291.

33. Das R, Nath G, Bohara S, Bhattacharya AB, Gupta V. Two unusual cases of acinic cell carcinoma: role of cytoogy with histological corelation. J Clin Diagn Res 2016;:21-22. doi: 10.7860/JCDR/2016/19753.8374

34. Alsayegh OR, Qazi I, Almurshed M, Al Mutairi MM, Alquanaee M. Acinic cell carcinoma primarily arising in ectopic salivary gland tissue within an intra-parotid lymph node: A case report. Otolaryngo (Sunnyvale) 2018;8(346):2. doi: 10.4172/2161-119X.1000346.

35. Biron VL, Lentsch EJ, Gerry DR, Bewley AF. Factors influencing survival in acinic cell carcinoma: a retrospective survival analysis of 2061 patients. Head Neck 2015;37:870-77.

36. Hoffman HT, Karnell LH, Robinson RA, Pinkston JA, Menck HR. National cancer data base report on cancer of the head and neck: acinic cell carcinoma. Head Neck 1999:297-309.

37. Patel NR, Sanghvi S, Khan MN, Husain Q, Baredes S, Eloy JA. Demographic trends and disease-specific survival in salivary acinic cell carcinoma: an analysis of 1129 cases. Laryngoscope 2014;124:172-78.

38. Neskey DM, Klein JD, Hicks S, Garden AS, Bell DM, El-Naggar AK Kies MS, Weber RS, Kupferman ME. Prognostic factors associated with decreased survival in patients with acinic cell carcinoma. JAMA Otolaryngol Head Neck Surg 2013;139:1195-202.

39. Yoshida EJ, Garcia J, Eisele DW, Chen AM. Salivary gland malignancies in children. Int J Pediatr Otorhinolaryngol 2014;78:174-78.

40. Spiro RH, Huvos AG, Strong EW. Acinic cell carcinoma of salivary origin. A clinicopathologic study of 67 cases. Cancer 1978;41:924-35

41. Gomez DR, Katabi N, Zhung J, Wolden SL, Zelefsky MJ, Kraus DH Shah JP, Wong RJ, Ghossein RA, Lee NY. Clinical and pathologic prognostic features in acinic cell carcinoma of the parotid gland. Cancer 2009;115:2128-37.
42. Skalova A, Sima R, Vanecek T, Muller S, Korabecna M, Nemcova J, Elmberger G, Leivo I, Passador-Santos F, Walter J, Rousarova M, Jedlickova K, Curik R, Geierova M, Michal M. Acinic cell carcinoma with high-grade transformation: a report of 9 cases with immunohistochemical study and analysis of TP53 and HER-2/Neu genes. Am J Surg Pathol 2009;33:1137-45

43. Miki H, Masuda E, Ohata S, Komaki K, Hirokawa M. Late recurrence of acinic cell carcinoma of the parotid gland. J Med Invest 1999;46:21316.

44. Hutchinson JC Jr. Acinic cell carcinoma of minor salivary gland origin Am J Otolaryngol 1981;2:54-58.

45. McGurk M. Extracapsular dissection for clinically benign parotid lumps reduced morbidity without oncological compromise. BJC 2003;89:1610-13.

46. Mantsopoulos K, Mueller S, Goncalves M, Koch M, Iro H. Completion surgery after extracapsular dissection of low grade parotid gland malignant tumors. Head Neck 2019;41:3383-88. doi: 10.1002/ hed. 2586

47. Mantsopoulos K, Koch M, Iro H. Extracapsular dissection as sole therapy for small low-grade malignant tumors of the parotid gland. Laryngoscope 2017;127:1804-7. doi: 10.1002/lary.26482

48. Bernier JL, Bhaskar SN. Lymphoepithelial lesions of salivary glands. Histogenesis and classification based on 186 cases. Cancer 1958;11:1156-79.

49. Perzin $\mathrm{KH}$, Livolsi VA. Acinic cell carcinomas arising in salivary glands: a clinicopathologic study. Cancer 1979;44:1434-57.

50. Jensen LM, Kiaer H. Acinic cell carcinoma with primary presentation in an intraparotid lymph node. Pathol Res Pract 192;188:226-31. 